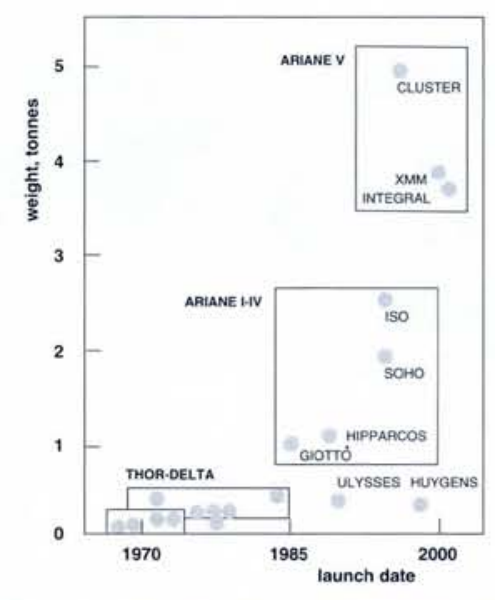

"hitting limits", both in terms of budgets and launchers. Hence, the time has come to think seriously about more new technology, notably miniaturization (the US Clementine spacecraft is a good example). Meanwhile, one has to be careful that partners are "reliable" when extending international cooperation to generate critical masses.

\section{Structures to Handle Facilities' Growth}

Astroparticle physics has been characterised by "dogs that did not bark" (null signals) involving such things as proton decay, magnetic monopoles, neutrinoless decay and dark matter. However, there have been some positive results and L. Maiani, the President of Italy's INFN, in reviewing underground and underwater facilities for astrophysics highlighted work on supernovae and solar neutrinos. He concentrated on the latter to illustrate the growing importance of large facilities such as the Gran Sasso Laboratory for astrophysics. Solar neutrinos from beryllium have been seen and the neutrino spectrum is inconsistent with the standard solar model. Two major new underground neutrino experiments come on-line shortly (Sudbury in 1995; Super Kamiokande in 1996) and there are good possibilities that Borexino will be approved. The main question now is if third-generation experiments will be needed. There is also continuing progress in the field of underwater (under-ice) neutrino telescopes, and longbaseline experiments will be needed to eventually check neutrino oscillations. With this expansion, there is a need to organize in some way the development of the various facilities. An inter-regional approach, that addresses increasingly finer structures, is one proposal for tackling an issue that will repeatedly challenge physics as it plans the ever more powerful and sophisticated instruments that are essential for future advances.

Luciano Maiani, on the left, spoke about Earth-based facilities for astrophysics.

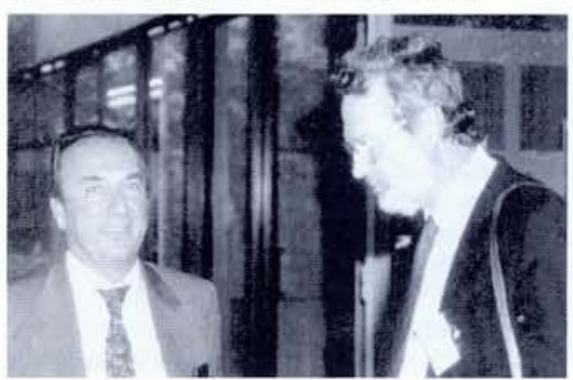

The evolution of ESA's Space Science Missions.

On the left: there has been a massive increase in the payloads as more powerful launchers became available.

On the right: the costs (in millions of Accounting Units) of the large CS-Class (Cornerstone) and M-Class (Mediumsized) missions have reached a plateau in spite of increasing complexity.

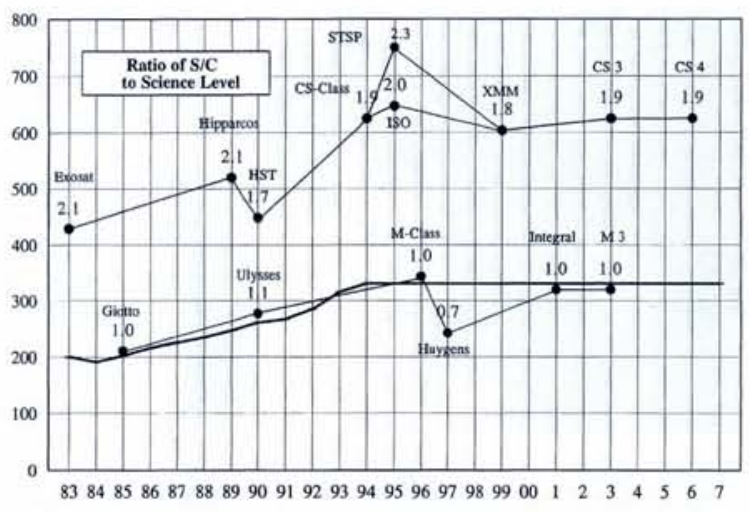

\title{
1994 EPS Large Facilities in Physics Conference ROUND-TABLE DISCUSSIONS
}

Three round-table discussions were held during the 1994 EPS Large Facilities in Physics Conference.

Large and Small Science

Challenges and Benefits of Large Facilities

Selection Procedures \& Priority Assessment for Future Large Facilities

\section{ROUND-TABLE: Large and Small Science}

\section{Promoting Opportunities Together}

Science has a place for all styles, whether collective, cooperative or small-group based. Attracting young people into the whole of science, both large- and small-scale, is appropriate and must be encouraged. Facilities can help by stressing ways to channel creativity and to transfer technology, and by training engineers.

The level of public support for science seems good, but the interest is not translated into more opportunities for young people since the mechanisms to promote science are inadequate.

Facilities, and more recently large cooperative science, is extending into the traditional small-science fields, with traditional large science providing a valid model.

Facilities have a special role to play in some countries, where special organizational structures may be appropriate.

Specific statistics about funding should help in reducing tension between the different branches of science.

Discussing the correct balance between large and small science was for Hans Chang (Director of the Dutch funding agency FOM) an irrelevant, emotional issue stirred up by governments seeking reductions in difficult economic times. Physics certainly needs to stand united, but this will be difficult when it comes to bread and butter issues, especially since certain fields need a boost to maintain them as interesting to areas outside physics. However, he questioned the wisdom of placing large facilities in a special category to insulate them somewhat because they are showing traditional small-science fields the way forward. The important feature today is that owing to improved communications and organization and increased size and internationalism we are now dealing with a new way to do science, and it is this that one should look at.

\section{Attracting Young People}

Aside from asking whether a particular field delivers high-quality results, the real question is whether or not large science attracts young people, for facilities will come to a premature end not from a lack of money, but through a lack of talented young people.
The large collaborations found at some facilities are often seen by those working in small groups elsewhere as being unattractive. Herwig Schopper, the conference chairman, stressed that the small-group culture in fact thrives inside most facilities. The real drawback is that their scientists now often only work on a few experiments in a lifetime, so there is a need to make better use of creativity.

After an animated discussion, speakers agreed that there was "a place for all" - for large collaborations and small universitybased groups. Any tension arising from differences in the working styles cannot be too great because people in both environments appreciate each others' efforts, especially in theory where ideas move freely. As Norber Kroó, EPS President and Director of the Insti-

\section{PANELISTS}

K.H. Chang, FOM, Utrecht

J.-M. Gago, LIP, Lisbon

C. Jarlskog, Lund (Chair.)

A. Santoro, CBPF, Rio di Janeiro

P. Wyder, MPI-CNRS, Grenoble

Y. Yamaguchi, IUPAP, Tokyo 


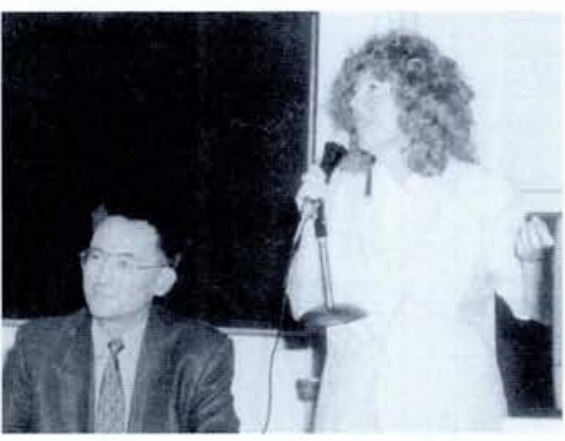

Hans Chang, on the left, with Cecilia Jarlskog, who chaired the round-table on large and small science.

tute of Solid State Physics in Budapest, put it, both soloists and symphonies are needed - the challenge is to optimize the outcome of both.

Alberto Santoro, a theoretician from the Brazilian Centre for Fundamental Physics in Rio di Janeiro, also wanted to rephrase the issue of large versus small science because he felt that it was often raised simply because one could discuss things elegantly, using sophisticated concepts. But for him the rea question also concerned young people as not enough is done to ensure that they are able to work in large facilities. In particular, in his region, where facilities are rare, young people will be lost to parts of science if the difficulties in financing international facilities persist. It was Yoshiro Yamaguchi, the President of the International Union of Pure and Applied Physics, who explained that large facilities are extremely precious in developing countries. Instead of trying to build up a broadly based small-science community from scratch, it is more effective to focus resources on part of the spectrum, and to use successes to expand into other fields.

\section{Defusing Emotion}

Nevertheless, the emotional issues attached to large and small science were to Peter Wyder, Director of the High Magnetic Field Laboratory in Grenoble, very real for they reflect real tensions. The emotions need to be controlled or they will explode, as happened in the lead up to the closure of the Superconducting Super Collider. Although his field of small science is growing up in the sense that larger facilities are crystallizing out of small groups of condensed-matter physicists distributed throughout the world, he had no easy answers as to how large and small science should coexist, especially because Hubert Curien had stressed that funds are not transferred between fields. Instead, he urged people in large facilities to be more sensitive for it is a "question of taste" whether high-temperature superconductors are more important than Higgs bosons.

To Burton Richter, President of the American Physical Society and Director of the Stanford Linear Accelerator Center, emotional aspects are a distraction because the real issue concerns the instruments needed to advance the various fields of physics. Traditional small science is moving towards larger facilities so in spite of the undoubted successes of small groups, the world has maybe moved on.

Herwig Schopper suggested that the best way to reduce the emotion amongst what he assumes is a rational community is to put facts on the table. For instance, one needs to clear up the misunderstanding that people in large facilities compared to universities have more resources simply because all their costs are included. To illustrate the point Hans-Christian Walter, head of nuclear and particle physics at the Paul Scherrer Institute Zurich, noted that at least one speaker had claimed that a particle physicist cost more than an average physicist whereas a recent study in Switzerland has shown that they cost about the same as a solid-state physicist. However, David Wallace, presently ViceChancellor at Loughborough and formerly a member of the former Science and Engineering Research Council in the UK, explained that his research council typically needed two-times more funds to support a physicis in "extremely large" science than an individual, university-based condensed-matter physicist. The factor dropped to three for scientists using facilities for structural studies, and there could be some offsetting by funds from other sources, including industry. Burton Richter then spoke of annual budgets at SLAC and CERN, and probably the European Synchrotron Radiation Facility (ESRF) as well, working out at about \$US 120000 per user. This compares with average government support in the US of SUS 150000 across all fields of science. So while a factor of two might be appropriate for particle physics (owing to the cost of running accelerators), an order of magnitude difference seemed unlikely. He was supported by figures given by Yves Petroff, the ESRF's DirectorGeneral, showing that an ESRF user costs about the same as a scientist working in the French CNRS research system. The comment that such figures are prone to double counting only reinforced the feeling that accurate statistics are lacking. However, much good quality data already exists so it is probably specific information which is needed (e.g., the evolution of the funds spent on scientists in various sub-fields)

\section{New Structures}

P. Ahluwalia who works for Canada's research council felt it was incorrect to equate large science with large facilities. One needs to go beyond instruments and look at organizational structures, for the communities involved in traditional small science now require the organizational support found in large science in order to participate in the human genome, global climate change and ocean drilling programmes (José-Mariano Gago, a particle physicist from Lisbon, referred to "large cooperative science" as distinct from large corporate science).

Many of the young participants contributed to the discussion.

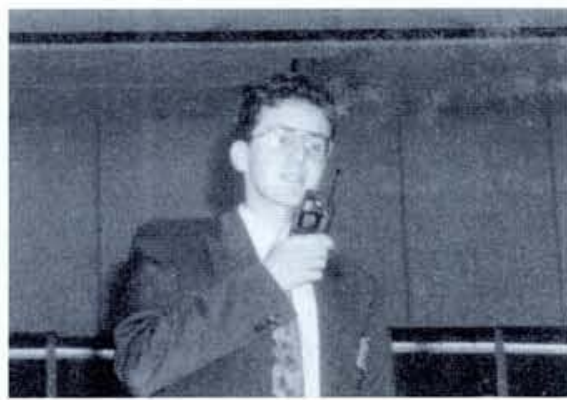

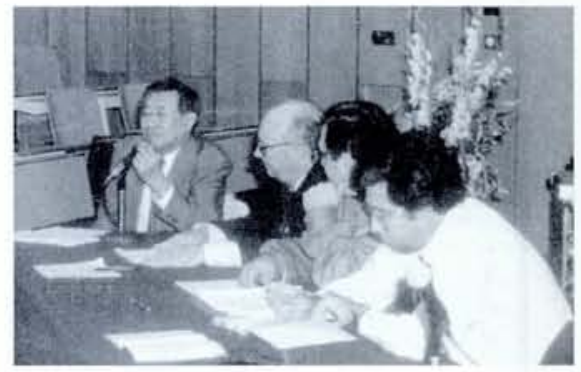

Yoshiro Yamaguchi, on the left, addressing the audience during the round-table. With him are (from the left) Peter Wyder, Alberto Santora and José-Mariano Gago.

Deszö Kiss from Budapest, formerly Director-General of the Joint Institute of Nuclear Research in Dubna, pointed out that the organizational aspects of large facilities are in fact already highlighted in smaller countries where such facilities potentially need a much larger share of science budgets. Starting from the premise that physicists would not wish to turn their backs on a field simply because the instruments it needs are large, Hungary's solution has been to fund space research and the like through a ministry for technical development. This is a delicate and far from ideal approach as the controlling body is not rooted in basic research. Nonetheless, it seems to work in Hungary.

\section{Generating Support}

Science is under stress today owing to reduced public (and hence political) support. Nonetheless, surveys show that a large proportion (about $70 \%$ ) of the general public is interested in knowing more about basic science. The problem is that they are poorly served because popularisers of science are lacking in the media and government. P. Verplancke, a young physicist from the Max Planck Institute for Plasma Physics, Garching, reproached his senior colleagues for not translating this public interest into more support because the growing number of young people interested in science do not have enough jobs.

Herwig Schopper felt it necessary to point out that alarmist projections in Germany of the lack of jobs were probably "completely wrong". In any event, young physicists should be encouraged to work in other fields. Physicists can undoubtedly bring valuable skills to areas outside research such as banking and government.

It was Burton Richter who explained in straightforward terms what needs to be done to stop support from "shrinking inexorably". One has to accept that a scientist's motives may only partly overlap with government's, and that physics once enjoyed military and politically motivated support. The time has come to spend much more time thinking collectively about how to explain the short and long-term benefits of science in intellectual and scientific terms. Herwig Schopper refined the objective by saying that it was not a question of "defending" science (certainly legitimate because scientists draw satisfaction from science) but of pointing out that in the long run society's problems can only be solved with more science.

Stress Multidisciplinarity

Herwig Schopper also wanted to clear up 
any misconception that large facilities as compared to small science do not provide an adequate training ground for young people by being too removed from economic realities. This was completely wrong because facilities teach one how to work on an industrial-style team, subject to schedules and budgets while using modern technology. The discussion then naturally turned to the use of facilities to train engineers. While this is a valid idea, it is probably insufficient to ensure that large facilities regain public esteem since other fields can do the same.

A proposal by Jacques Arvieux, an accelerator physicist from Saclay, to identify from the start ways to make facilities multidisciplinary, or at least sufficiently well known to be able to take on multidisciplinary studies at a later stage, will only go part of the way towards the ideal of "natural multidisciplinarity" with its potential for generating public support. However, multidisciplinarity will help address one of the challenges that JoséMariano Gago felt large science has not tackled successfully. This is the question of transferring physicists as opposed to say engineers to other fields when a facility is exhausted. Large science is being held up as

\section{ROUND-TABLE: Challenges and Benefits of Large Facilities}

\section{Two Plus Two is Negotiable}

Promoting the realization of new facilities is the greatest challenge facing facilities in physics.

Making unjustifiable claims to the public about the direct social benefits of facilities is unproductive. A better approach is to develop the link between facilities-based experimentation and technological development.

Traditional models for preparing and planning facilities remain valid, at least in some fields, provided allowance is made for the effects of increased scale, but it is not clear if these models can be translated to small-science fields, where facilities are becoming more common.

Access is the second most important challenge. New technology may help improve access - but too much should not be expected in the short-term, and harmful sociological effects must be minimized.

The archiving and the electronic distribution of data generated by facilities appear to be both necessary and feasible in most fields of physics to ensure access.

Training is clearly a major secondary benefit of facilities (after the ability to acquire new knowledge).

Universities should accept that facilities offer enhanced scope; they should interact with facilities in tackling some complementary problems and their students should be involved in constructing equipment. Complementary measures such as special schools may be needed if students cannot easily participate in building up experiments at facilities.

Facilities promote international cooperation that lies at the heart of science, but opportunities need reappraisal in the light of political changes.

Facilities play natural role in technology transfer, but discussion with industry in appropriate terms is needed to convince it that facilities provide not only customers but also benefits.

In setting the agenda for the Challenges and Benefits of Large Facilities round-table, Ken Pounds, Chief Executive of the UK's Particle Physics and Astronomy Research Council, singled out the realization of future facilities as being the greatest challenge certainly at the scientific and technical levels, but primarily at the political level in assuring funding for a number of years. Proper exploitation comes next as facilities have a responsibility to ensure access to all those who can take advantage. Several aspects immediately came to mind, both technical and organizational. The main benefit is undoubtedly a model for traditional small-science fields which are now developing facilities as it has demonstrated the capacity to end programmes when they are "exhausted". But it has only been partially successful in transferring physicists.

Yoshiro Yamaguchi explained that multidisciplinarity, and its corollary of reuse in other fields, has been the basis of the KEK laboratory's successful demonstration of what can be achieved with limited budgets. The KEK originated with medical, solid-state and nuclear physicists coming together to build a multidisciplinary facility with very respectable facilities for medical work, neutron spallation, and mesons. This is not the general rule, for a wasteful "feudalism" has emerged in some fields that started out together but now have their own institutes, and experiments which are not interchangeable.

Feudalism must be strong in view of the paradox that in spite of international cooperation in science working extremely well, the time-lag for transfer between fields remains very long. Paul Kienle, the NuPECC Chairman, felt one should start to tackle this difficult problem by extending multidisciplinarity in universities.

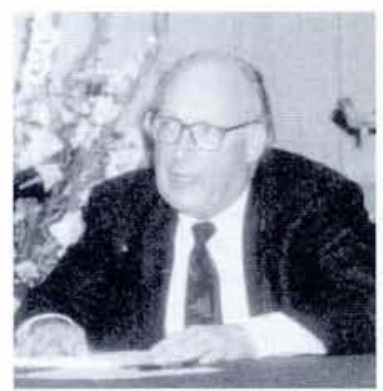

Peter Wyder, Chairman of the EPS Condensed Matter Division.

together a plan. But it will still be necessary to adopt most of the elements of the traditional model, namely to define and report on the scientific needs and the needs of the user community via community-based bodies (e.g., ICFA), to involve users in the definition and planning stages, not only to ensure good science but also to develop political support, and to identify a host laboratory that plays an important but not a dominant role.

Particle physics, unlike synchrotrons and similar sources, has to integrate two types of equipment (the accelerator and detectors). This has traditionally been done by forming detector collaborations when a facility begins to be created. The collaborations then interact with the host laboratory in identifying the optimum ingredients (technical, scientific and personnel), presenting plans, identifying resources and integrating elements of collaborations that are not selected. High technical and scientific standards result, which may not be the case if the host laboratory dictated say the make-up of a collaboration. ICFA, in coordinating advice on high-energy facilities, now feels that with much fewer large facilities and detectors being realized, its guidelines will have to be modified to include the concept that regions participating in detector collaborations should also be partly responsible, both "financially and intellectually", for constructing the facility.

\section{Access - Physical and Remote}

Claude Détraz, the Director of $\ln _{2} P_{3}$ (France's national institute for nuclear and particle physics) spoke of the ample evidence showing that working groups in large(regional) and medium-sized (national) facilities are of "19th century size" and typically number a handful of people (this characteristic is so important that he suggested using the group size as a management indicator). Second, problems to phase out a facility are minimized by ensuring a small staff and by taking a very positive attitude to reuse and to the transfer of the facility to other fields. The best way to maintain these features is by keeping strictly to the concept of an open, collective users facility.

So the main challenge is to ensure small groups with access that is determined as fairly as the outcome of the scientific review of proposals. However, travel costs are a very real barrier to access, but in distributing support there are no "easy criteria" for esta-

blishing if groups benefit equally because so

\section{Showing the Way}

John Peoples, the Director of FERMILAB and Chairman of the International Committee for Future Accelerators (ICFA), first recalled how high-energy physics has traditionally initiated, planned and launched its facilities. For practical reasons, the model for the future (the "new era" where there can be no unnecessary duplication) will initially involve discussion by several regions followed by a limited number, and maybe even one, putting

\section{PANELISTS}

C. Détraz, CNRS, Paris

V. Kadyshevsky, JINR, Dubna

M. Malacarne, EC, Brussels

J. Peoples, FERMILAB, Batavia, IL

K.A. Pounds, PPARC, Swindon (Chair.)

R.A. Ricci, INFN, Legnaro 
many parameters are involved. More data is needed and possible solutions maybe include data distribution and the remote control of experiments.

John Peoples pointed out that unlike astronomy, most fields of physics have not worried too much about data archival. One may now have to adopt the astronomers' model by having catalogues that can be reused after a suitable initial period. Some speakers thought archiving data would be difficult in practice as raw data often needs considerable manipulation before being useful. However, some manipulation is already being done by facilities. So while one may argue about the sort of information that should be stored (storing raw data is best if one can afford it, because the ultimate value is so unpredictable), it is now only a matter of "carrying the idea further". Burton Richter also endorsed the idea as it is not a huge task to transform data so that it is easily accessible to anyone other than members of the "in group" that performed an experiment.

David Wallace commented that one should go further by exploring opportunities offered by information technology as a whole because topics such as the use of information highways to provide electronic access have not roused much interest so far. Herwig Schopper pointed out an important advantage of the remote control of experiments is that scientists would be kept where they belong, namely in their universities and institutes participating in normal academic life.

Speakers agreed that it is unwise to take considerations of the relative costs of remote and electronic access too far since they extend beyond the simple question of travel needs. For instance, building experiments to satellite specifications may rule out remote control (David Saxon, Glasgow University). Indeed, Thierry Courvoisier, an astronomer from Geneva, in recalling the work to operate one of the European Southern Observatory's telescopes remotely, emphasized that remote control is "not around the corner" since costs place serious bandwidth limitations.

More generally, introducing remote access will entail a "regrettable" change in the way science is done (Burton Richter), with further fragmentation of a community. Both John Peoples and Ken Pounds stressed efforts to limit excessive fragmentation (into, e.g., data analyzers and data takers) as it is essential to keep an involvement in all aspects of facilities via personal contacts. One also risked loosing control of projects, notably their cost, if a group simply handed over a list of specifications without there being a close feedback to allow unnecessary requirements to be modified (overspecification is a well known "cost driver" in contracted-out space-based instrumentation)

\section{Facilities Essential for Training}

Claude Détraz pointed out that facilities generally provide small groups with access to order-of-magnitude better equipment than they could otherwise expect - groups which would become "irrelevant" if they did not rub shoulders in the highly competitive world of facilities, where some of the physics that is done could simply not be imagined without the resources which are made available. It is therefore inappropriate to attempt simple comparisons between the budgets for university groups and for facilities. And it is certainly not axiomatic that increased support for faci-

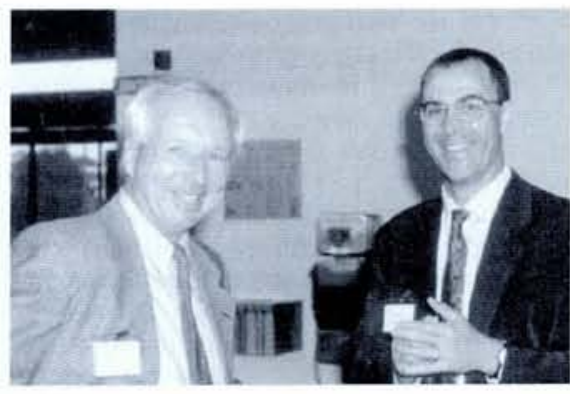

Marco Malcarne, on the right, described how the European Community sees the benefits and challenges of large facilities.

lities - or what he called collectively organized science - translates into a reduced capacity for university groups.

In having young people regenerate facilities and in exposing them to the benefits of world-class research opportunities offered at facilities, young scientists should be involved in building equipment, even if industry is responsible. For one does not learn much "by looking at specifications" (John Peoples). In those cases where user communities tend to work as small groups at different facilities without the interest or the resources to build equipment, relying instead on being supplied with all their requirements, there is still a need for students to understand how data is collected. In the case of small countries without major facilities, students are often not too enthusiastic about having to work elsewhere in order to learn about equipment. Special international schools modelled on the wellestablished European and US accelerator schools may then be needed.

Maurice Jacob from CERN who co-chaired the conference, pointed out that facilities often compete with universities by offering courses; they also often have a fair number of young physicists generating data who have difficulty finding positions elsewhere. Universities have similar people, only they tend to be analyzing data. Renato Ricci from Legnaro and Chairman of the EPS Nuclear Physics Division, felt a "balance" needed to be struck, with the two types of institutions sharing their complementary problems and benefits.

\section{Next Steps in International Collaboration}

To Vladimir Kadyshevsky, the DirectorGeneral of the Joint Institute for Nuclear Research (JINR) in Dubna, science by its very nature is international (in the words of a Russian writer, "if it is national it is already not a science"). International cooperation is therefore a challenge, and the main issue is how to move towards a closer but "well balanced" collaboration in science following recent political developments in eastern Europe. He called for a "symmetrical step" by inviting western countries to join the 18 Member States of JINR as there are now no political obstacles. He argued that the JINR is a worthy candidate as it already serves as a bridge between east and west - a role it plans to enhance by creating a new international university. It also operates as a worldclass users laboratory, with a newly elected Scientific Council to ensure high scientific standards and major facilities either operational, under construction or being planned, the last category having been international from the beginning.

\section{Technology a Key Element}

For Marco Malacarne who helps run the European Union Framework programme's access to (existing) large installations activity, the technological challenge of facilities is a key element. It is now necessary to avoid duplication in developing peripheral equipment, which is becoming increasingly sophisticated and beyond the capabilities of a single group (the next Framework programme will in fact stimulate transnational cooperation in developing equipment). The technological challenge means that facilities link the worlds of scientific research and economic activity, between which the beneficial feedback is not as linear or as large as some once thought. But it is there, and it needs to be enhanced.

Renato Ricci tackled the same issue from the other end of the spectrum. He was aware that physics facilities do not appear to have the same degree of public support as say the genome project and large astronomical observatories. However, using the all-important mass media to generate support for physics-based facilities does not mean claiming that a particular facility gives direct social benefits. In his view, the challenge instead is to convince the public at large of the importance of seeking new knowledge through experimentation. If it is then appreciated that physics essentially deals with and needs actual experiments (contrary to what some eminent physicists think), the public will hopefully understand that physics strives for new techniques and advanced technology. Since facilities are the organizations that exploit technical opportunities, people will in due course appreciate that facilities reflect and stimulate a vigorous technological development. It will of course be necessary to explain that the ultimate social benefits are significant, but the main challenge is to stress this link between facilities-based experimentation and technology. There is a danger of overdoing the argument, and it was Norbert Kroó who warned the audience about "promising more than one knows or is able to solve" as this may do may harm than saying nothing.

Hans Ott from Zurich and a member of the management board of the Paul Scherrer Institute commented that not only the public but also industry needs to be convinced of the value of physics. There seems to be a "gap" between what physics delivers and what industry says it wants in terms of research as opposed to orders for equipment. This is probably overstating the problem because although countries participating in large facilities push for a good industrial return, their industries have always been interested in technology transfer from facilities. Burton Richter also expressed surprise at remarks about industry's apparent lack of interest in research. He concluded that the gap must be larger in Europe than in the US, where industry is the strongest supporter of university-based long-term fundamental research (because industry itself cannot afford it). Maybe more dialogue is needed so that industry can better understand science. In having this it may be wise to follow Herwig Schopper's advice to adapt to another world - to another way of saying things. He told the story of a politician who is reported to have said: "to you scientists two plus two is four; to us politicians it's negotiable". 


\section{ROUND-TABLE: Selection Procedures and Priority Assessment for Future Large Facilities}

\section{The Basket Finds Favour}

Different perspectives, and the balance between them, come into play when setting priorities for facilities, with political aspects dominating.

Consideration of a proposal, including its difficult non-rational aspects, at the appropriate governmental and political level will lead to a successful outcome provided there is general agreement on the scientific goals.

Appropriate bodies and channels are needed at and between the various levels separating a proposed facility's user community from the decision-makers. Several types of suitable bodies exist at some levels and in some fields, so there are models available for ways to fill in what is missing.

Both bottom-up and top-down approaches have been used successfully to promote facilities at the European level and in general there are no rules for deciding which is best. The situation is much less promising at the international level.

The basket approach of sharing out a suite of regional and international projects is robust enough to serve as a way for governments to reach decisions on projects that are increasing in size and scale. Implementing the approach needs some formal steps.

Deciding whether or not a proposed facility is international in scope and access is maybe too difficult for scientists to take alone, especially since there is a natural tendency to promote and operate facilities according to national interests.

The round-table Selection Procedures and Priority Assessment for Future Large Facilities came to some definite conclusions concerning most of the themes that it was asked by Hubert Curien, the chairman, to discuss. The main themes were:

- the complementarity of scientific and political approaches in selection procedures;

- the role of international organizations and governmental bodies;

- the type of advice deciders seek from users;

- the importance of advising governments on a wide scientific front.

- what determines if a facility should be national, regional or global in scale.

\section{Science Proposes, Politics Disposes}

Promoting a facility calls for an acute awareness that different communities have very different perspectives when they set priorities for fundamental research. Herber Walther, the Director of the Max-Planck Institute for Quantum Optics, Garching, noted that, broadly speaking, scientists think in terms of originality, quality, feasibility, infrastructure, and value for universities; industrialists worry about spin-off, general opportunities for exploitation and technical significance, while politicians have in mind possibilities for regional development, society's needs, and the publicity value. Moreover, the balance between the various priorities changes. Right now government attaches more importance to industrial and social needs, and the public is wary of certain fields such as nuclear physics.

\section{PANELISTS}

H. Curien, Univ. P. \& M. Curie, Paris (Chair.)

K. Gaemers, NIKHEF-K, Amsterdam

L. Maiani, INFN, Rome

J.R. O'Fallon, Dept. of Energy,

Washington, DC

F Praderie, OECD, Paris

B. Richter, SLAC, Stanford, CA

$\mathrm{H}$. Walther, MPI, Garching
For Luciano Maiani, the President of the Italy's institute for nuclear and particle physics (the INFN), approving projects is "in the end a political issue", coming after discussion between politicians and scientists. However, for this stage to be reached the scientific relevance must be clearly established as being at the frontiers, and the planned facility must be accepted by a large community. Many of the failures in promoting facilities arose because the sectors of science not directly affected were not in agreement. Facilities must be "science driven" with scope and goals set by scientific needs (J.R. O'Fallon, US Department of Energy). They must also be presented to government at an early stage, and later at a formal level to ensure that the desired funding is reasonable and the political implications acceptable.

Herwig Schopper pointed out that setting priorities becomes difficult for both scientists and politicians when issues with non-rational answers are raised, such as how to distribute resources between different fields and how to determine the interval between successive large projects (using natural human time-scales seems to be the sensible answer).

\section{Forums are Needed}

It becomes increasingly difficult to discuss needs and priorities as one moves from the community level, through community/government dialogue to intergovernmental negotiation. From her perspective as Secretary of the OECD's Megascience Forum, Françoise Praderie argued that "things work" at the scientific level. Integrating what scientists want into the broader political perspective at the national level has also be shown to work if special structures are set up (such as France's ministerial advisory committee on large instruments that examines needs throughout science). Government-level agencies play a valuable role in co-ordinating the views of scientists and government, but here there is an imbalance, at least in Europe. Governments apparently communicate to the agencies extensive descriptions of long-term strategic plans whereas science does not.

On moving further up the chain one finds that we are "less well equipped at the international level" (Praderie), although some examples of the essential elements are already in place. For instance, international, community-based discussion bodies such as ICFA and its European counterpart ECFA (one of a number of European-level discussion groups, including academies of sciences and the scientific unions) that interface between the scientific community and government have already shown their usefulness. Fields other than particle physics have "missing links" - missing lines of communication - that could be filled by bodies of the ICFA type.

Finally, at the intergovernmental level, the first step towards creating a environment where governments can coordinate approaches efficiently has been taken by forming the OECD Megascience Forum.

Norbert Kroó pointed out that there are some general issues in setting priorities such as the need to achieve a proper "balance" between intellectual potential (which is fairly uniformly distributed) and economic capacity (which is not). Physical societies are well placed to advise on such a problem (i.e., the effects of a siting decision on the brain drain)

\section{Appropriate Channels to Deciders}

Examining how existing facilities were promoted gives some ideas on what type of advice deciders seek from users and how it is communicated. Europe has been fairly successful in creating facilities as there are at least seven physics-related Europeanscale facilities and organizations. Herbert Walther felt that the best way to promote a facility is the bottom-up approach where an ad hoc community-based discussion group

Ken Pounds, on the right, opening the round-table on the challenges and benefits of large facilities. With him are (from the left), John Peoples, Renato Ricci, Vladimir Kadyshevsky, Claude Détraz, and Marco Malacarne.

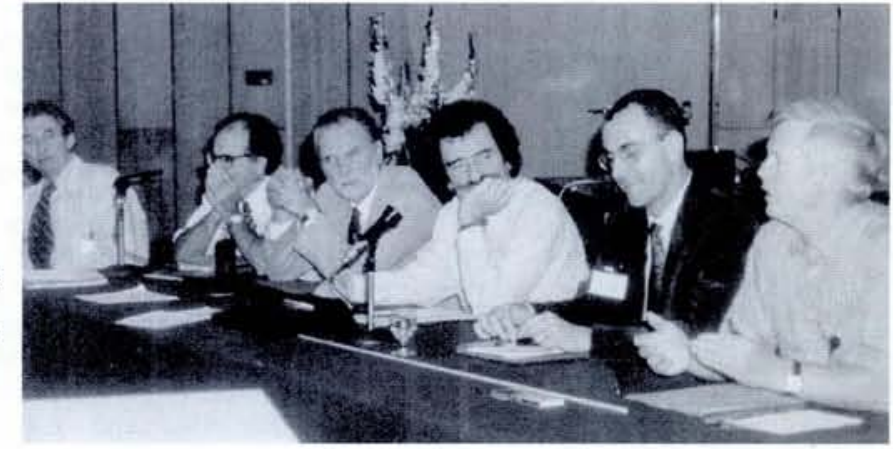


initially seeks a consensus. However, some European institutions have also successfully promoted facilities, notably the European Science Foundation in establishing the ESRF, so this avenue should not be ignored.

The record is not so brilliant at the worldscale where among the few projects, the International Thermonuclear Experimental Reactor (ITER) project has problems stemming from its regional bias. ITER evolved out top-down discussions in a sub-group called the Attali committee that prepared joint projects in many topics (not just science) for meetings of the heads of governments of the G7 countries. This subgroup represents one of the relatively few international-level discussion bodies with interests in science.

The variety of at least partially successful approaches supported Luciano Maiani's view that there are no general rules for the discussions between science and politicians (apart from a need for "fair play", which science can best ensure by putting forward widely accepted frontier projects).

\section{Baskets Across a Broad Front}

It was Luciano Maiani who introduced Burton Richter's basket concept that aims to help the "selling" of projects to government by introducing a mechanism to distribute the economic benefit of hosting a facility. One puts various large projects into a basket and has government decide upon major issues such as a priorities and siting, because whatever scientists think, it is politicians "who decide such things". The advantage is that one can envisage the simultaneous approval of a collection of projects in different regions to neutralise extraneous factors ("why approve a 1000 M\$US collider in Japan when the US has a trade deficit").

However, speakers emphasized that the basket items should be reasonably "homogeneous" (Maiani) in the sense that the items are recognized as equally significant by the scientific community. They should also have similar time-scales so that "everybody need not wait for everybody" (Günter Flügge, ECFA Chairman), a feature that is seen as an insurmountable disadvantage by some. Finally, the organizations involved should be of similar size (Curien) for space agencies have tried to a limited extent the basket approach, but it did not work because of hugely different scales.

Ensuring homogeneity may be difficult if one follows Hubert Curien's advice to have

Kai Siegbahn, on the left, with Robert Wilson who concluded the conference with a lively and humorous account of how Fermilab in the US was built up.

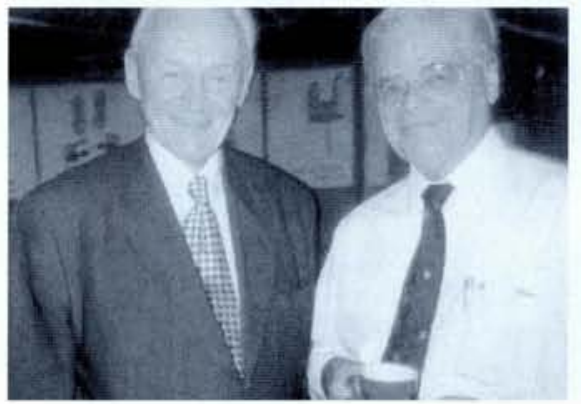

the basis of acceptance for the basket items in say physics as large as possible to offset any reduced level of political support compared to other disciplines (having a generous basket is feasible in physics because non-physicists need physics-based facilities, e.g., biologists carrying out structural studies using neutrons and the like). It will be even more tricky if one includes the proposal by Francoise Praderie that scientists should add technological items to the basket (as for the ESRF when a wind-tunnel was thrown into the pot during intergovernmental negotiations). But in the final analysis, she felt that one can realistically only hope for implementation of the basket approach within a fairly specific area such as groundbased telescopes. Maiani backed this view: the basket can be made to succeed "in certain circumstances", and it will be in spite of what scientists say so "we should get used to it" and understand how it works.

On the time-scale aspect, Hubert Curien argued that the differences in time-scales between various projects are not large enough to "destroy the basket" because major facilities take a long time to realize, construction times are similar (and should anyway be short), and because parts of the process (e.g., the R. \& D. phase) do not need to be coordinated between different projects.

On the problem of having the basket operated by organizations of different size and scale, perspectives have changed; the large space agencies are not so flourishing that they can "dominate entirely". International cooperation based on a basket even with Russia in a weak position - will probably work much better now than in the past.

Perhaps the key issue is that if the basket concept is to work at all it must be formally agreed upon by governments (they need to agree on what type of project should go in, and on carrying out a project once the basket is decided). A young physicist from the audience suggested forming an organization analogous to the somewhat tarnished World Bank to operate the scheme. There is indeed some movement towards "filling the vacuum" (Curien). It comes as a fall-out of the informal meeting of the socalled "Carnegie group" of science ministers of the G7 countries and Russia that takes place every few years (the first was at the Carnegie Foundation in the USA in 1992 and the next will be in September 1995). The group is considering some form of permanent body to replace the OECD Megascience Forum that was essentially set up following initiatives by Allan Bromley, a former Scientific Adviser to the US President, to help governments exchange information about the basket of projects.

\section{National versus International}

Deciding whether to have a national or an international facility is much more complicated than a simple evaluation of costs, which can be very misleading because other factors are equally important. These include the advantage of having many scientists involved (as in the world-scale genome project), and the size of the user constituency. One should also not forget that internationalisation entails additional costs.

Luciano Maiani felt that the scientific community itself has little difficulty in determining if a facility should be national, regional or global, even in fields such as astrophysics where the move to larger facilities is quite rapid. Herbert Walther felt it could also judge if a national facility is preferred because industry is involved or because one needs to train people.

Hubert Curien was not so sure scientists alone could judge adequately because, to put it bluntly, "nobody wants to be second class, even for a national facility". There is an understandable desire to seek the best, which naturally leads to thinking in international terms. This problem is neutralised by using national facilities to address particular kinds of frontier problems, or instance, those needing a relatively large amount of user time (which is less restricted at a national facility) or a long duration (national facilities tend to have long life-spans).

Generally speaking, however, "national tendencies will have to be subjugated for the broad benefit of science", especially when a community promotes an international facility (there is a tendency to keep priorities too nationally-based for too long). Burton Richter's advice was that if you are in any way thinking internationally "get your partners in from the beginning", as was done for the ESRF which he held up as an excellent model (straightforward structures, inexpensive operation, minimum treaty requirements). Be aware also that things will be become more difficult as the project progresses: the initial R. \& D. phase will by relatively painless compared to when site decisions are taken and people have to think about moving country.

Promoters of international facilities should also not be too "narrow in their thinking" when considering access. If budgets are tight it is natural to want to have users support the operation of a facility, especially if they come from equally well-developed countries. This must be resisted otherwise there will be "a trade war in science". It can be resisted because although the books may not balance in a given area, they are sure to balance across the whole of science.

P.G. Boswell 